\title{
Intracardiac Thrombus Revealing Coronavirus Disease 2019 (COVID-19). About a Case, Renaissance University Hospital Center in N'Djamena (Chad)
}

\author{
Ali AA ${ }^{1,6^{*}}$, Bolti $\mathrm{MA}^{2,6}$, Kaboré $\mathrm{A}^{1}$, Brahim $\mathrm{S}^{3}$, Aomi $\mathrm{A}^{3}$, Abdessalam $\mathrm{MB}^{4}$, Adam $\mathrm{Y}^{2}$ and Abdelmadjid $\mathrm{Z}^{5}$ \\ ${ }^{1}$ Department of Cardiology, Renaissance University Hospital Center, N'Djamena, Chad \\ ${ }^{2}$ Department of Medicine, Renaissance University Hospital Center, N'Djamena, Chad \\ ${ }^{3}$ Department of Radiology, Renaissance University Hospital Center, N'Djamena, Chad \\ ${ }^{4}$ Department of Emergency, Renaissance University Hospital Center, N'Djamena, Chad \\ ${ }^{5}$ Department of Cardiology, Reference University Hospital Center, N'Djamena, Chad \\ ${ }^{6}$ Faculty of Human Health Sciences of N'Djamena, Chad
}

*Correspondence: Adam Ahamat Ali, Department of Cardiology, Renaissance University Hospital Center, N'Djamena, Chad

Received on 22 June 2020; Accepted on 10 July 2020; Published on 16 July 2020

Copyright (C) 2020 Ali AA, et al. This is an open access article and is distributed under the Creative Commons Attribution License, which permits unrestricted use, distribution, and reproduction in any medium, provided the original work is properly cited.

\begin{abstract}
Severe acute respiratory syndrome coronavirus 2 (SARS-CoV-2) called COVID-19 is often associated with thrombotic complications, especially in severe cases. We report a case of COVID-19 revealed by a right intraatrial thrombus to emphasize the risk of thromboembolic diseases linked to this pathology. He was a young subject, 41 years old, with no notable history. He complained of asthenia and precordialgia. Echocardiography showed the presence of a right intraatrial thrombus and laboratory tests confirmed COVID-19. Under medical treatment combining antithrombotics, chloroquine and azithromycin, the thrombus regressed, and the markers of inflammation were normalized after 12 days. One month later, the patient remained clinically stable with normal echocardiography.
\end{abstract}

Keywords: COVID-19, intracardiac thrombus, N'Djamena - Chad

Abbreviations: SARS-CoV-2: severe acute respiratory syndrome coronavirus 2; VTED: venous thromboembolic disease; CRP: C-reactive protein; PT: prothrombin time; INR: international normalized ratio

\section{Introduction}

In December 2019, the city of Wuhan in Hubei Province, China, saw an epidemic caused by severe acute respiratory syndrome coronavirus 2 (SARS-CoV-2) called COVID-19. This epidemic gradually spread to other regions and other 
countries, becoming a pandemic. In April 28, 2020, the number of infected patients were more than 3,000,000 cases with more than 210,000 deaths in 185 countries [1]. Chad noted its first case of COVID-19 in March 2020.

Respiratory symptoms are at the forefront, with a potential evolution towards an acute respiratory distress syndrome, since COVID-19 mainly affects the respiratory tract [2, 3]. COVID-19 interacts with the cardiovascular system at several levels, increasing morbidity in patients with underlying cardiovascular conditions and causing myocardial damage and dysfunction [1]. The risk of venous thromboembolic disease (VTED) appears to be very high in patients with COVID-19, especially in severely ill patients [4]. It is not only VTED, but also arterial thrombosis, hemodialysis filter, oxygenation equipment by extracorporeal membrane and pulmonary microthrombi [4, 5]. This coagulopathy is associated with a poor prognosis [6]. The case we are reporting illustrates this thrombotic risk well. He was a 41-yearold patient who was presented with an intracardiac thrombus and whose course was favorable under anticoagulant therapy combined with chloroquine and azithromycin.

\section{Observation}

Mr ES, 41 years old, with no particular history, was hospitalized in our department on May 09, 2020 for the management of right intraatrial thrombosis in a febrile context. We noted the appearance of physical asthenia associated with precordialgia three days before his hospitalization, motivating the patient to consult a liberal cardiologist, hence his orientation at our level.

On physical examination, we noted: its body mass index at $28 \mathrm{~kg} / \mathrm{m}^{2}$, its oxygen saturation at $98 \%$ in ambient air, its temperature at $39.5^{\circ} \mathrm{C}$, its blood pressure at $110 / 65 \mathrm{mmHg}$, and its heart rate at 122 beats/min. Cardiopulmonary auscultation was normal. He had no signs of heart failure. On the electrocardiogram, there was a sinus tachycardia at 122 cycles/min, an $\mathrm{S} 1 \mathrm{Q} 3$ aspect with a $\mathrm{QRS}$ axis at $+110^{\circ}$ and negative less specific $\mathrm{T}$ waves in the extended anterior. Blood tests showed signs of inflammation with a C-reactive protein (CRP) level at $174 \mathrm{mg} / \mathrm{l}$, a leukocytosis at $21200 / \mathrm{mm}^{3}$, severe thrombocytopenia at $23000 / \mathrm{mm}^{3}$, a D-dimer level at $71402 \mathrm{ng} / \mathrm{ml}$ and a prothrombin time (PT) level at $68 \%$ with international normalized ratio (INR) at 1.32 .

On echocardiography (Figure 1), the heart chambers were not dilated with preserved biventricular systolic ejection fractions. There was a right intraatrial thrombus measuring 110/90 mm, very mobile with the movements of the tricuspid valves. There was no valve disease. Pulmonary systolic arterial pressures were normal at $30 \mathrm{mmHg}$. The pericardium was free. The CT scan without injection (Figure 2) showed bilateral ground-glass opacities. In view of the COVID-19 pandemic context, and these very suspicious data, the patient was removed for a diagnostic test of COVID-19 and put on the following treatment: Lovenox ${ }^{*} 1 \mathrm{ml}$ every $12 \mathrm{~h}$, chloroquine $600 \mathrm{mg} / \mathrm{d}$ for $10 \mathrm{days}$, azithromycin $500 \mathrm{mg}$ loading dose then $250 \mathrm{mg} / \mathrm{d}$ for 5 days.

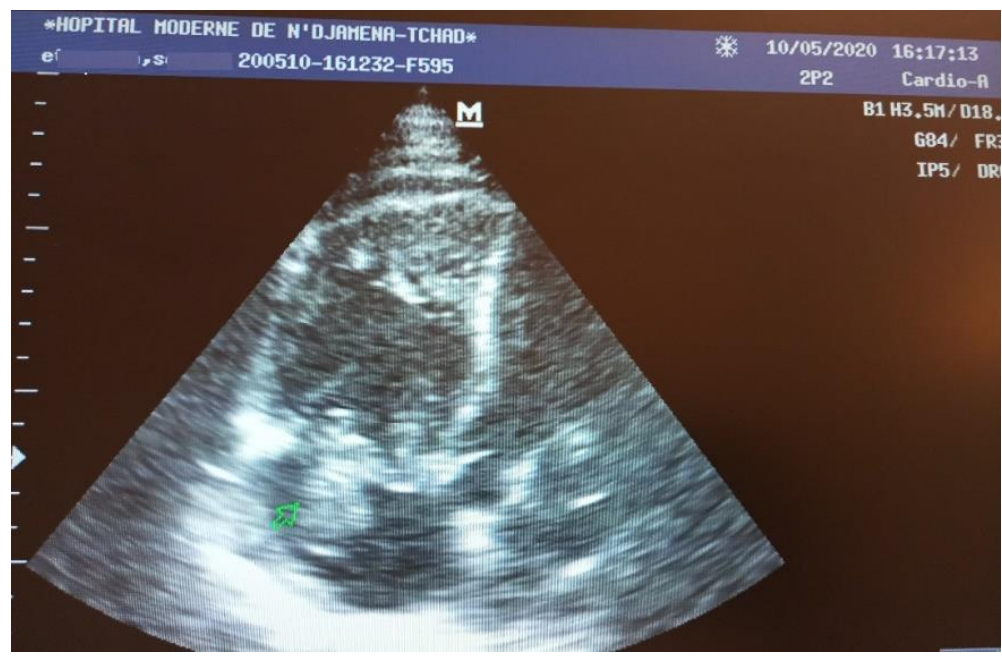

Figure 1: 4-cavity section echocardiography showing the right intraatrial thrombus. 


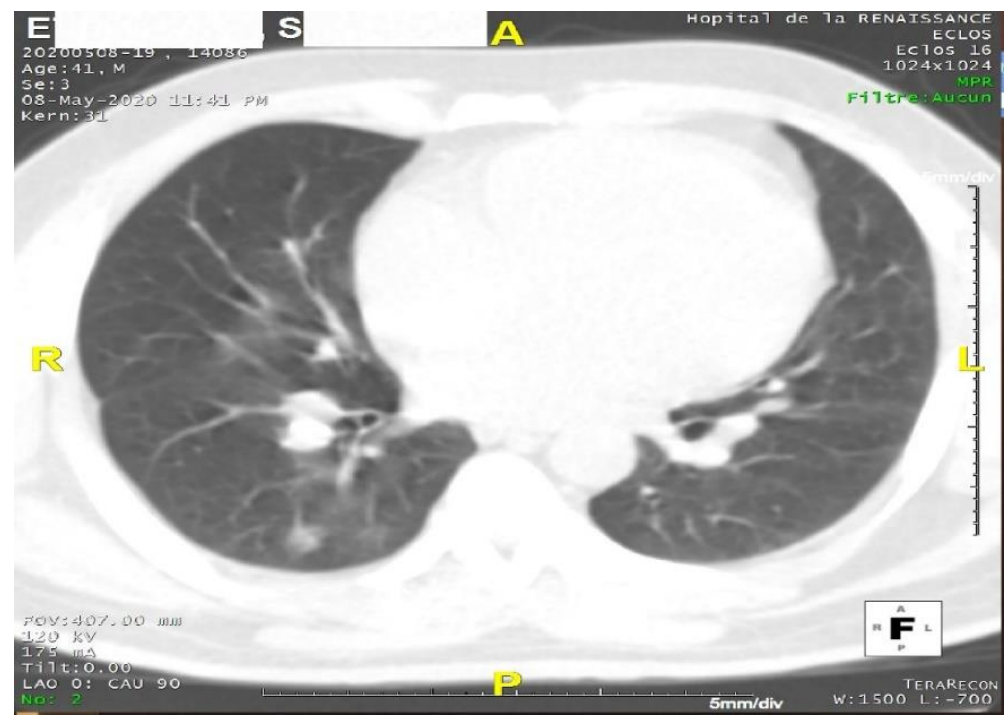

Figure 2: CT scan presenting pulmonary ground-glass opacities.

After $48 \mathrm{~h}$ of treatment, the diagnostic test for COVID-19 returns positive. Echocardiography revealed a persistence of the right intraatrial thrombus without modification of its size. We decided to thrombolyse the patient with streptokinase 1,500,000 IU intravenously in $2 \mathrm{~h}$. Post-thrombolysis echocardiography showed migration of the thrombus into the right ventricle without changing its size (Figure 3). The initial treatment was maintained while combining Coumadin $5 \mathrm{mg} / \mathrm{day}$ then $10 \mathrm{mg}$.

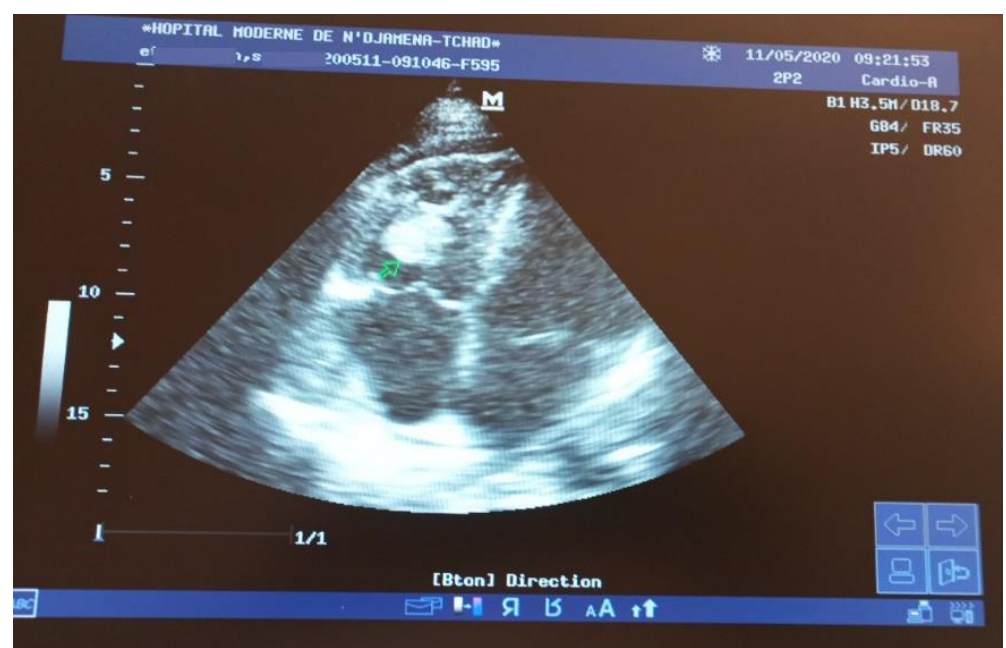

Figure 3: 4-cavity section echocardiography showing the migration of the thrombus to the right ventricle.

On the 12th day of hospitalization, the patient was clinically asymptomatic. The biological parameters were almost normalized (CRP at $9 \mathrm{mg} / \mathrm{l}$, platelet count at $492,000 / \mathrm{mm}^{3}$, D-dimers at $600 \mathrm{ng} / \mathrm{ml}$ ). The PT was $42 \%$ with an INR at 2 on antivitamin K. The control echocardiography showed a complete regression of the thrombus (Figure 4). The patient was released with the following treatment: Coumadin $10 \mathrm{mg} /$ day for 3 months and chloroquine $200 \mathrm{mg} / \mathrm{day}$ for 4 weeks. One month later, the patient remained clinically stable with normal echocardiography. 


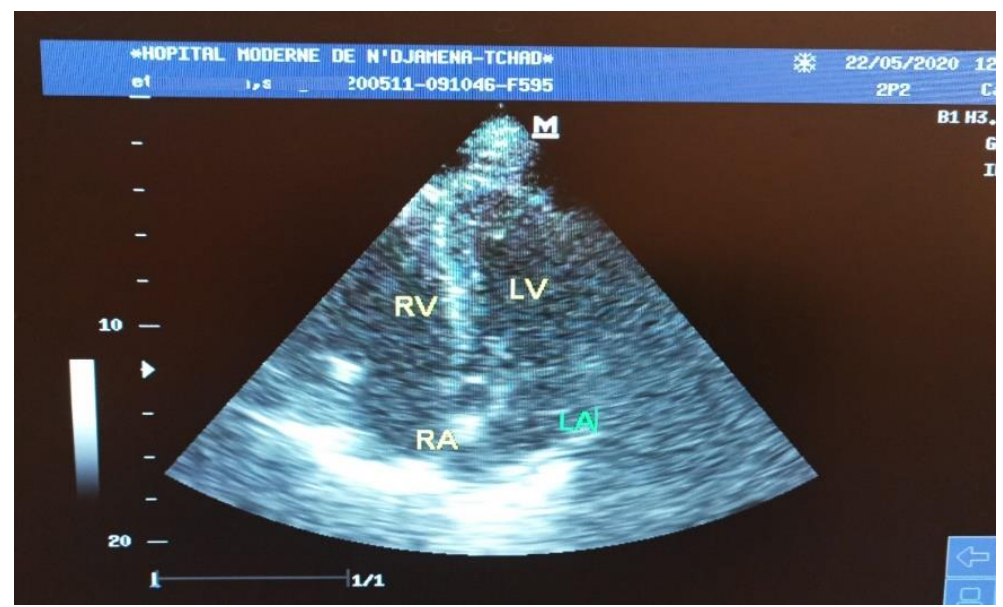

Figure 4: 4-cavity section echocardiography presenting the complete regression of the thrombus. RV: right ventricle; RA: right atrium; LV: left ventricle; LA: left atrium.

\section{Discussion}

The risk of VTED in the context of COVID-19 remains unclear. This risk seems very high among critically ill patients but also exists in patients with less symptoms, such as our patient. Several retrospective cohorts have reported hypercoagulability in patients with COVID-19 [5, 7-9]. This prothrombotic state observed, is probably of multifactorial origin. On one hand, patients with severe COVID-19 often combine several thrombotic risk factors (a potentially high age, reduced mobilization, an infectious state, and respiratory decompensation). On the other hand, a systemic inflammatory response syndrome with a procoagulant storm of cytokines and possibly a direct action of the virus on endothelial cells, thus causing a major activation of coagulation with an extremely high factor VIII and von Willebrand level high $[4,5,10,11]$. This can sometimes lead to disseminated intravascular coagulopathy [12]. It should be noted that thromboembolic complications can occur despite prophylactic or therapeutic anticoagulation. Helms et al. [5] showed in a prospective cohort that 42.7\% (64/150) of patients with COVID-19 on anticoagulant therapy had developed thrombotic complications including $16.7 \%(25 / 150)$ of pulmonary embolism. This may mean that the anticoagulant targets for COVID-19 are probably higher and warrant prospective studies. A panel of experts currently recommends prophylactic anticoagulation, although some experts consider the intermediate dose or the therapeutic dose to be reasonable. Recent recommendations on the management of coagulopathy, based on the monitoring of standard coagulation markers (D-dimers, prothrombin time, fibrinogen and platelet count), have been advanced by the International Society on Thrombosis and Haemostasis (ISTH) [5, 12].

Our patient progressed very well with the curative dose of fractional heparin after the failure of thrombolysis. The thrombus regressed and markers of inflammation were normalized. We do not know the part of chloroquine and azithromycin in this good development but certainly favorable if we refer to the study carried out by Million et al. [13] who concluded that the early administration of the combination hydroxychloroquine and azithromycin reduces the complications and mortality linked to COVID-19.

\section{Conclusion}

COVID-19 appears to induce an unusual prothrombotic state. Very careful thromboprophylaxis is warranted even in the absence of severe symptoms.

\section{Conflicts of Interest}

The authors declare no conflicts of interest. 


\section{References}

1. Clerkin KJ, Fried JA, Raikhelkar J, et al. COVID-19 and cardiovascular disease. Circulation. 2020;141(20):1648-55.

2. Haeck G, Ancion A, Marechal P, et al. COVID-19 et maladies cardiovasculaires [COVID-19 andcardiovascular diseases]. Rev Med Liege. 2020;75(4):226-32.

3. Davenne E, Giot JB, Huynen P. Coronavirus et COVID-19: le point sur une pandémie galopante [Coronavirus and COVID-19: focus on a galopping pandemic]. Rev Med Liege. 2020;75(4):218-25.

4. Casini A, Fontana P, Glauser F, et al. Risque thrombotique veineux induit par le SARS-CoV-2 : prévalence, recommandations et perspectives. Rev Med Suisse. 2020;16(692):951-54.

5. Helms J, Tacquard C, Severac F, et al. High risk of thrombosis in patients with severe SARS-CoV-2 infection: a multicenter prospective cohort study. Intensive Care Med. 2020;46(6):1089-98.

6. Tang N, Li D, Wang X, et al. Abnormal coagulation parameters are associated with poor prognosis in patients with novel coronavirus pneumonia. J Thromb Haemost. 2020;18(4):844-47.

7. Chen N, Zhou M, Dong X, et al. Epidemiological and clinical characteristics of 99 cases of 2019 novel coronavirus pneumonia in Wuhan, China: a descriptive study. Lancet. 2020;395(10223):507-13.

8. Wang D, Hu B, Hu C, et al. Clinical characteristics of 138 hospitalized patients with 2019 novel coronavirusinfected pneumonia in Wuhan, China. JAMA. 2020;323(11):1061-69.

9. Guan WJ, Ni ZY, Hu Y, et al. Clinical characteristics of coronavirus disease 2019 in China. N Engl J Med. 2020;382(18):1708-20.

10. Escher R, Breakey N, Lämmle B. Severe COVID-19 infection associated with endothelial activation. Thromb Res. 2020;190:62.

11. Mehta P, McAuley DF, Brown M, et al. COVID-19: consider cytokine storm syndromes and immunosuppression. Lancet. 2020;395(10229):1033-34.

12. Thachil J, Tang N, Gando S, et al. ISTH interim guidance on recognition and management of coagulopathy in COVID-19. J Thromb Haemost. 2020;18(5):1023-26.

13. Million M, Lagier J-C, Gautret P, et al. Early treatment of COVID-19 patients with hydroxychloroquine and azithromycin: A retrospective analysis of 1061 cases in Marseille, France, Travel Medicine and Infectious Disease. Travel Med Infect Dis. 2020;35:101738. 